Sharif University of Technology
Scientia Iranica
SCIENTIA
I RAN I CA

Review Article

\title{
Upcoming challenges of future electric power systems: sustainability and resiliency
}

\author{
M. Fotuhi-Firuzabad*, A. Safdarian, M. Moeini-Aghtaie, R. Ghorani, \\ M. Rastegar and H. Farzin
}

Center of Excellence in Power System Control and Management, School of Electrical Engineering, Sharif University of Technology, Tehran, Iran.

Received 7 March 2015; accepted 25 July 2015

\author{
KEYWORDS \\ Power industry \\ challenges; \\ Power industry \\ solutions; \\ Future power systems; \\ Resilient power \\ systems; \\ Sustainable power \\ systems.
}

\begin{abstract}
Going back and taking a quick glance at the history of developed countries prove that prosperity of any society is tightly intertwined with resiliency and sustainability of its preliminary infrastructures. Surely, in modern societies, electricity is among the most important infrastructures whose resiliency and sustainability are a key driving force toward development of the society. This is verified by the fact that since the industrial revolution, per capita electricity consumption has been taken as a key index showing the level of economic development and standard of living in a country. This paper focuses on the concept of resiliency and sustainability of electric power systems. The paper, initially, introduces the concept and evaluation procedure of power systems resiliency. Then, it strives to introduce the most challenging issues faced by resilient and sustainable power grids. The challenging issues are electricity load growth, energy crisis, environmental emissions and climate changes, unexpected events, aging infrastructures, and cyber challenges. Then, the most effective solutions proposed by power industry scientists and engineers are discussed. The solutions are asset management, renewable energy resources, demand response, controlled islanding and micro-grids, automation, selfhealing, and monitoring systems. Finally, a typical sustainable and resilient power system is described.
\end{abstract}

(C) 2016 Sharif University of Technology. All rights reserved.

\section{Introduction}

The concept of resiliency, which was stimulated by environmentalism, focuses upon the requirements to counter the occurrence and impact of catastrophic events on urban areas. In particular, the concept of resiliency is used to describe the ability of cities and regions in moving toward more 'safe' and 'sustainable'

*. Corresponding author. Tel.: +982166165921 E-mail addresses: fotuhi@shairf.edu (M. Fotuhi-Firuzabad); safdarian@sharif.edu (A. Safdarian); moeini@sharif.edu (M. Moeini-Aghtaie); ghorani_rahim@ee.sharif.edu (R. Ghorani); mohammadrastegar@shirazu.ac.ir (M. Rastegar); farzin@ee.sharif.edu (H. Farzin) communities [1]. As electric power infrastructures have contributed a lot to the safety and sustainability of communities, upgrading the current infrastructure to a resilient one is one of the major goals which portray the future resilient urban areas.

Electric power system, with its humble beginning in the 1880s, has been matured into a large-scale industry. Taking the role of a basic necessity for modern societies, electricity consumption around the world experiences a fast growing trend. In response, the worldwide electricity production nowadays has reached near 21 billion kilowatt-hours per year (see Figure 1) [2]. As new gears and machines have been made based on electricity, human life quality has been 


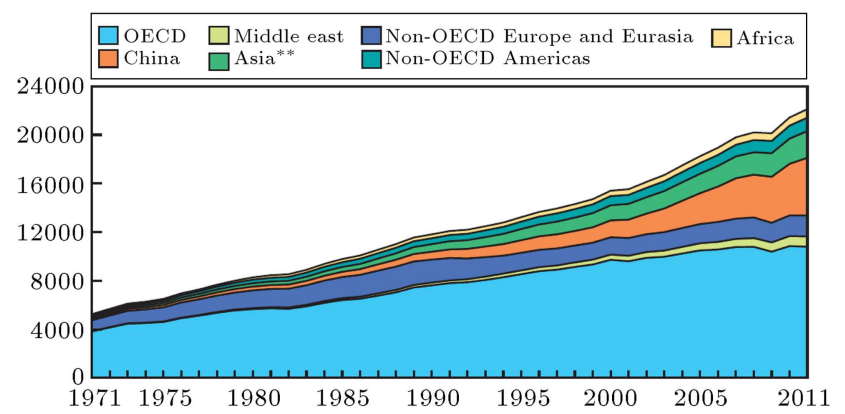

Figure 1. Electricity production around the world (TWh)

intertwined more and more with continuity and quality of electricity services. The proliferation of electric devices in human life has obliged the power industry to pay a greater attention to the service reliability.

On the other hand, electricity industry encounters a large number of challenging issues in meeting reliability requirements of the society. Electric power systems are among the most complicated man-made structures through the history with a large number of components scattered in vast areas. This, beside aging infrastructures, growing loads, natural disasters, energy crisis, and proliferation of renewable energies, makes meeting the reliability requirements a very difficult task. On the other hand, huge and almost always growing needs for intensive capital reinforcements in power systems are in an obvious contradiction with tightly limited budgets in this industry. These all force the industry to explore some innovative ideas useful for utilizing existing electricity infrastructures in a more effective manner thereby guaranteeing a sustainable and resilient system. Asset management, self-healing systems, precise monitoring and visualization systems, prompt automation systems, controlled islanding and micro-grids, demand response, and renewable energy sources are among the most effective ideas which were proposed by power system engineers to propel the industry toward a more sustainable and resilient power system.

A sustainable power system should be able to tolerate unexpected events, such as equipment outages, severe weather conditions, natural disasters, and fuel shortages, to name just a few. Synonymously, in a sustainable system, customer service continuity and reliability should be preserved during such events. A resilient power system is able to effectively and quickly recover the likely load interruptions following an unexpected event such as equipment outages and natural disasters. The concept of asset management is a cost-effective way to efficiently manage asset related procedures, i.e. procurement, operation, maintenance, and disposal of assets, and to help system owners to satisfy their financial goals while meeting benchmarked reliability and resiliency standpoints. Advanced mon- itoring infrastructures provide system operators with more precise situational awareness and allow them take more effective remedial actions. Automated power systems provide system operators with remote control actions, which in turn result in prompt remedial actions. The controlled islanding and micro-grids by isolating autonomous areas of the system intend to serve electricity needs of end users which are located in healthy areas. Demand response is an effective load shaping tool which can be utilized to alleviate operational limits such as network overloads and undervoltages. Finally, renewable energy sources by declining the share of fossil fuel-fired generating units in load procurement can be an effective solution for energy crisis. Therefore, moving toward a sustainable power system calls for changes not only in the way electrical energy is supplied, but also in the way it is consumed.

Based on the above discussions, one can come to this point that power industry is faced with several challenging issues that should be properly addressed to promise a bright future for the system. In addition, as mentioned heretofore, a large number of efficient as well as economical solutions have been found to counter the critical issues. As a complementary to the published works in this area, this paper describes the major challenges encountered by the industry to move toward a resilient and sustainable power system. In addition, this paper reviews the most effective ways available to enhance the system resiliency and sustainability following unpredicted events including both endogenous and exogenous failures. A brief explanation on how the ways cover concerns about resiliency and sustainability of power systems is the other goal of this paper. Discussing the challenges and solutions, an envisioned power system, which is equipped with effective tools to reach an appropriate level of resiliency and sustainability, is also introduced.

\section{Resiliency concept and evaluation in power systems}

As mentioned in the previous section, over the past decades, the international society and specifically power utility managers have paid a great attention to preventing catastrophic losses and managing disruptive impacts of both man-made and naturally happening threats and hazards. To this end, there exist several different definitions for a resilient system which is immune to both man-made and naturally occurring threats. In the following, a few of the most relevant definitions for "resilience" are given [3]:

- Resilience is "a measure of the persistence of systems and of their ability to absorb change and disturbance and still maintain the same relationships between populations or state variables" [4]; 
- Resilience is "the capacity to cope with unanticipated dangers after they have become manifest, learning to bounce back" [5];

- Resilience is "the capacity to adapt existing resources and skills to new situations and operating conditions" [6];

- Resilience is the "ability to resist, absorb, recover from, or successfully adapt to adversity or a change in conditions" [7].

Resiliency is a system concept which is related to some other system concepts such as reliability or survivability. Actually, in the literature on electrical engineering, resiliency and reliability have almost the same meaning. The term reliability is the probability that a device or system performs its purpose adequately for the period of time intended under the operating conditions encountered. When it comes to the power grid, reliability can be defined as the ability of the grid to perform its intended function, which is serving electricity needs of consumers and other preliminary infrastructures in a continuous and of course economic manner. In the electric utility industry, system reliability has two fundamental aspects of adequacy and security. Adequacy refers to the existence of sufficient generation, transmission, and distribution facilities to produce and transport electric energy to end users taking specified outage events into account. Security, however, refers to the ability of a system to withstand any disturbances arising within the system. These include local and widespread disturbances as well as unexpected sudden loss of generators, network components, or loads resulting in system instability and cascading outages. Needless to mention, a reliable power system refers to a system which is both adequate and secure.

In order to recognize adequacy and security, power system conditions can be described by several operating states in terms of the degree to which adequacy and security considerations are satisfied. These operating states are designated as normal, alert, emergency, extreme emergency, and restorative as shown in Figure $2[8]$. These states are determined in terms of the degree to which security margins are satisfied. In the normal state, the system is capable to serve the existing total load. In this state, sufficient margin is available such that any likely disturbance, specified by some criteria, can be tolerated. A criterion such as the loss of any single component depends on the planning and operating philosophy of the service provider. The system is in the alert state if all the constraints are within limits but there exist some disturbances which cannot be tolerated by the system and following which electricity service interruption is not avoidable. In the emergency state, some of the system operational constraints are violated. In this state, the system is

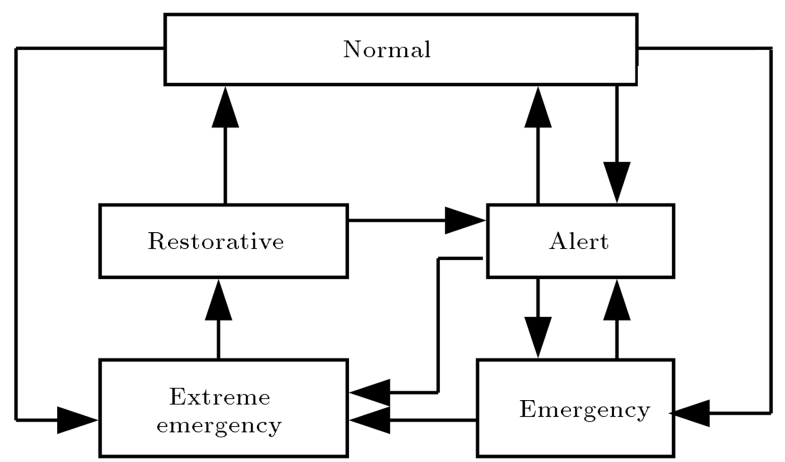

Figure 2. System operating states diagram.
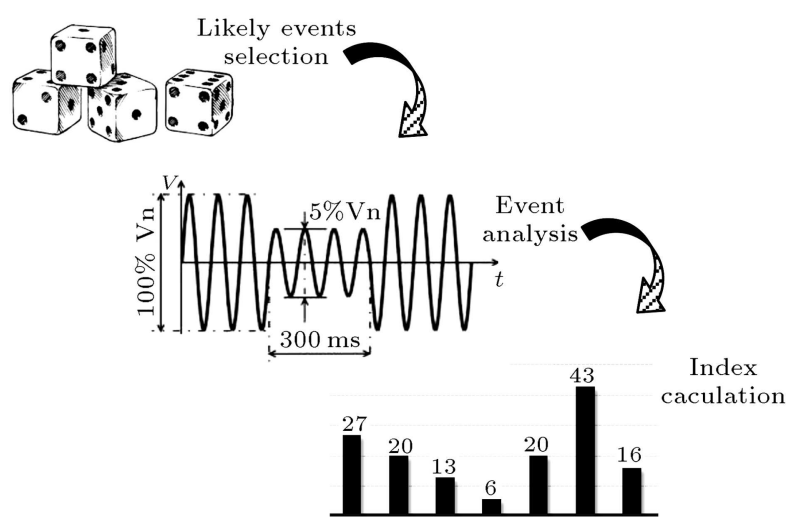

Figure 3. Three steps of reliability assessment procedure for a power system.

still intact but appropriate remedial actions must be taken into account to restore the system to at least the alert state; otherwise, the system will transfer from the emergency state to the extreme emergency state. In the extreme emergency state, system operational constraints are violated and some load points experience electricity service interruption.

According to the above model, for a system, probability of being in the fivefold operating states illustrates the degree of system well-being. In order to estimate probabilities of the states, a three-step procedure, which is shown in Figure 3, must be performed. As can be seen, in the first step, likely events, including both man-made and naturally happening disturbances and hazards, are selected. In the next step, the selected events are analyzed and their circumstances are obtained. Clearly, some of the selected events lead to violations of operational constraints, which can be mitigated by appropriate remedial actions, and some result in service interruptions. The achieved consequences associated with the selected events are combined with their occurrence probability to form state probabilities as reliability indices in the third step.

The reliability evaluation procedure, although seems to be straight, is a very challenging process mainly due to the required data and the huge number of 
likely events. The former origin of difficulty goes back to the fact that almost all of man-made and naturally happening disturbances are stochastic in nature and their occurrence highly depends on several affecting parameters such as weather condition. For example, the failure rate associated with power system components usually increases during severe weather conditions. In order for an analysis to lead to reasonable and accurate results, likely events and their occurrence probabilities must be determined through comprehensive analyses of historical recorded data of the system during different conditions (e.g., different weather conditions). The latter origin of difficulty in reliability assessment procedures goes back to the enormous number of power system components which are scattered in vast areas with different weather conditions. This substantially increases the number of likely events which can occur in the system. Note that analyzing a huge number of events is exhaustive and computationally expensive. For these reasons, there have been developed sorts of commercially available software packages for both data collection and reliability analyses. The Iran Grid Management Company (IGMC), which is in charge of the Iranian power system, under the umbrella of a project with Sharif University of Technology (SUT), studied almost all of the available worldwide power system reliability assessment software packages, and based on their pros and cons, it is going to develop a comprehensive software package for the national grid.

It can be concluded from the above discussion that the system must be able to resist likely disturbances as well as to recover to its normal condition following any disturbances. Even though resiliency is a more comprehensive concept, both resiliency and reliability include some aspects of resistance against disturbances and recovering from them. Both aspects become more meaningful when dealing with very largescale and complex systems such as power grid.

\section{Challenges}

This section describes the major challenging issues which may be encountered while the power industry intends to move toward a resilient and sustainable system. The issues are load growth, energy crisis, emissions and climate changes, unexpected events, aging infrastructure, and cyber challenges.

\subsection{Load growth}

Electricity load growth is a challenging issue which should be considered by the power industry. The system load increases as new customers are added to the grid or existing customers add new appliances or replace their existing equipment with devices that require more power. Load growth is influenced by many factors

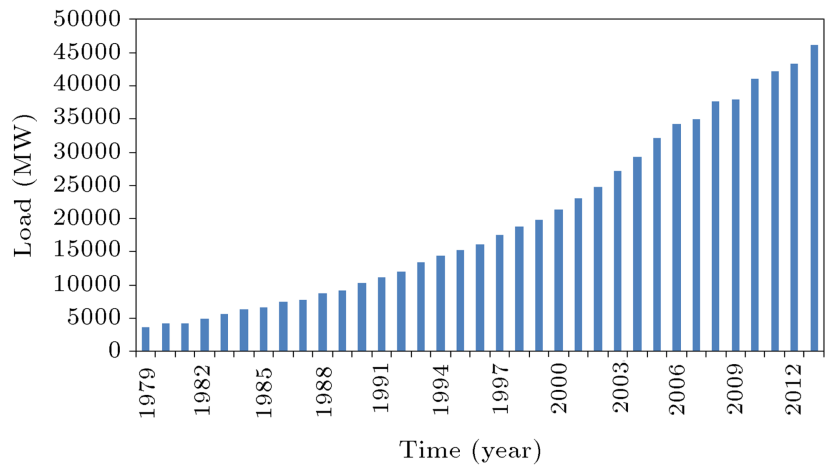

Figure 4. Annual peak load variation in Iran from 1979 to 2013 .

including the national economy, income per capita, power management, prices, policies, and conservation. The Annual Energy Outlook 2007 (AEO2007) [9], prepared by the Energy Information Administration (EIA), presents long-term projections of energy supply, demand, and prices to 2030. According to this report, the mean incremental growth rate of annual electricity consumption will be $1.55 \%$ due to new uses of electricity. It may vary in different countries. For instance, Figure 4 [10] shows the load demand variation in Iran from 1979 to 2013, where the load growth on average is $7 \%$.

Besides the mentioned load growth, proliferation of electric vehicles, which is triggered by environmental concerns, will add a significant load to the power industry. A typical plug-in electric vehicle requires $0.2-0.3 \mathrm{kWh}$ of charging power for a mile of driving. Assuming average daily trip with 30-40 miles of length, electric vehicles need 7-10 $\mathrm{kWh}$ of electrical energy daily. These load growth, if it is not managed effectively, may degrade power systems reliability. In addition, unbalanced load growth, resulting from unequal single-phase and double-phase loads such as plug-in vehicles, could result in degradation of power quality, increased harmonics and voltage problems, and increasing line losses.

\subsection{Energy crisis}

Secure and price-consistent sources of primary energies are among critical prerequisites for modern societies. Primary energy is referred to as an original energy form which can be found in the nature and has not been subjected to any transformation process. The major sources of primary energies are fossil fuels (coal, oil and natural gas), biofuels-wood, wooden wastes, agricultural wastes, etc. Figure 5 [11] demonstrates the share of different primary energy forms in worldwide energy consumption. As can be seen, oil, coal, and natural gas has made up almost $78 \%$ of primary energy production.

As mentioned earlier, fossil fuels have the largest share in the sources to produce electricity worldwide. 


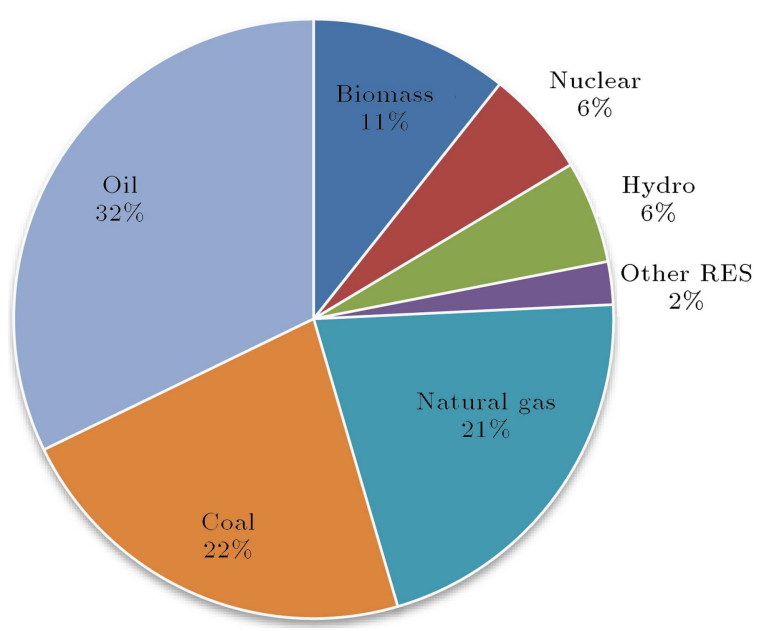

Figure 5. Worldwide consumption of primary energy sources.

Table 1. World reserves of natural gas.

\begin{tabular}{lccc}
\hline & $\begin{array}{c}\text { Proved reserves } \\
\text { (trillion cubic } \\
\text { meters) }\end{array}$ & $\begin{array}{c}\text { \% of } \\
\text { world } \\
\text { reserve }\end{array}$ & $\begin{array}{c}\text { Remaining } \\
\text { years of } \\
\text { extraction }\end{array}$ \\
\hline World & 187 & 100 & 56 \\
Iran & 34 & 18 & 209 \\
Russian & 33 & 18 & 56 \\
Federation & & & \\
Qatar & 25 & 13 & 160 \\
Turkmenistan & 18 & 9 & 272 \\
US & 8 & 5 & 12 \\
Saudi Arabia & 8 & 4 & 80 \\
United Arab & 6 & 3 & 118 \\
Emirates & & 3 & 170 \\
Venezuela & 6 & 3 & 119 \\
Nigeria & 5 & 2 & 55 \\
Algeria & 5 & &
\end{tabular}

However, fossil fuel reserves are not uniformly distributed over the earth. Tables 1 to 3 [12] respectively show the share of different countries from the remaining resources of natural gas, coal, and crude oil. As can be seen, a large number of the primary energy reserves are owned by a few countries. Therefore, countries with inadequate reserves of fossil fuels face serious concerns about primary energy availability since functionality of their power systems is highly dependent on others. Besides, according to the most optimistic forecasts done, the reserves of fossil fuels last for 109 years for coal, 56 years for natural gas, and 53 years for crude oil. Based on the above discussions, power industries, whose main sources of primary energy depend on fossil fuels, will encounter the challenging issue of energy crisis.
Table 2. World reserves of coal.

\begin{tabular}{lccc}
\hline & $\begin{array}{c}\text { Proved reserves } \\
\text { (trillion cubic } \\
\text { meters) }\end{array}$ & $\begin{array}{c}\text { \% of } \\
\text { world } \\
\text { reserve }\end{array}$ & $\begin{array}{c}\text { Remaining } \\
\text { years of } \\
\text { extraction }\end{array}$ \\
\hline World & 860938 & 100 & 109 \\
US & 237295 & 28 & 257 \\
Russian & 157010 & 18 & 443 \\
Federation & & & \\
China & 114500 & 13 & 31 \\
Australia & 76400 & 9 & 177 \\
India & 60600 & 7 & 100 \\
Germany & 40699 & 5 & 207 \\
Ukraine & 33873 & 4 & 384 \\
Kazakhstan & 33600 & 4 & 289 \\
South Africa & 30156 & 4 & 116 \\
Colombia & 6746 & 1 & 76 \\
\hline
\end{tabular}

Table 3. World reserves of crude oil.

\begin{tabular}{lccc}
\hline & $\begin{array}{c}\text { Proved reserves } \\
\text { (trillion cubic } \\
\text { meters) }\end{array}$ & $\begin{array}{c}\text { \% of } \\
\text { world } \\
\text { reserve }\end{array}$ & $\begin{array}{c}\text { Remaining } \\
\text { years of } \\
\text { extraction }\end{array}$ \\
\hline World & 1669 & 100 & 53 \\
Venezuela & 298 & 18 & 299 \\
Saudi Arabia & 266 & 16 & 63 \\
Canada & 174 & 10 & 127 \\
Iran & 157 & 9 & 117 \\
Iraq & 150 & 9 & 132 \\
Kuwait & 102 & 6 & 89 \\
United Arab & 98 & 6 & 79 \\
Emirates & & & \\
Russian & 87 & 5 & 22 \\
Federation & 48 & 3 & 87 \\
Libya & 37 & 2 & 42 \\
Nigeria & & & \\
\hline
\end{tabular}

\subsection{Emissions and climate changes}

A power system must be environmentally friendly to support a sustainable society. Therefore, alleviating climate changes and environmental concerns are among challenging issues which are encountered by the power industry.

Moreover, since greenhouse gases generated by electric power plants are much easier to monitor and control than emissions from other sources such as vehicles, the electricity sector has always been considered as a primary target in emission control programs. Fossil fuels burnt to supply the global electricity demand account for releasing annually over 7700 million tons 
of carbon dioxide $\left(\mathrm{CO}_{2}\right)$, which is equivalent to $37.5 \%$ of total $\mathrm{CO}_{2}$ emissions. It is predicted that the annual $\mathrm{CO}_{2}$ emission will surpass 15000 million tons by 2020 [11]. Nowadays, in worldwide electricity production, coal continues to have the largest share by $38 \%$, which provides electricity with high greenhouse gases and emissions.

\subsection{Unexpected events}

Unexpected events are the major contributor in jeopardizing power systems resiliency and sustainability. As mentioned heretofore, power systems have been designed and operated to withstand a great majority of disturbances while being able to supply to customers. However, despite the arduous efforts to build a resilient and sustainable system, unexpected disturbances always threaten security and functionality of the system. In addition, interconnected nature of the system increases the probability of fault propagation, which can interrupt the service to a large number of customers. In the next paragraph, main roots of system events are initially categorized followed by a brief discussion on the expected consequences of outages and blackouts.

In the electrical engineering context, faults are categorized based on their electrical nature and duration. Accordingly, faults are generally divided into two major groups of open and short-circuit faults, which can be further classified based on the number of involved electrical phases [13]. Following an event, repair/replacement expenses, likely losses of the service provider, and likely damage costs to customers are the three main contributors to the overall damage cost. It is clear that damaged components must be repaired/replaced to fully restore the system functional- ity. This procedure incurs maintenance or replacement costs to the service provider. Besides, since the system, whose electricity service is interrupted, is unable to supply to customers, the revenue from selling electricity to the customers is lost as well. At last, monetary damages and loss of comforts are imposed on customers who experience service interruptions. Among the three terms, since prosperity of customers' activities is highly intertwined with electric energy, any interruption in the services paralyzes customers; as a consequence, interruption costs to customers are much more than the losses of maintenance and service providers [14]. In fact, the type of customers and outage duration are the two important factors that determine the damage to customers. To delineate the subject, Table 4 lists the estimated customer interruption costs for different outage durations and customer types [15].

Blackouts or large outage events are the most catastrophic events that can happen in a power system. These catastrophic events usually originate in either natural disasters such as floods and earthquakes or propagation of component outages through power systems. Cascading outages, which are defined as a sequence of dependent failures, lead to power system weakness and may spread through the system and cause blackouts. A propagation sequence can be due to the fact that power systems are weakened following an outage as well as due to protection system malfunctions or system operator errors. In such catastrophic events, extensive interrupted areas along with usually long restoration time worsen the situation and exacerbate their monetary losses and social consequences compared to events with limited affected areas and short durations. To demonstrate both the vulnerability of modern power systems and the catastrophic conse-

Table 4. Estimated average electric customer interruption costs in 2008, in US Dollars.

\begin{tabular}{cccccc}
\hline \multirow{2}{*}{ Interruption cost } & \multicolumn{5}{c}{ Interruption duration } \\
\cline { 2 - 6 } & $<\mathbf{5} \mathbf{~ m i n}$ & $\mathbf{3 0} \mathbf{~ m i n}$ & $\mathbf{1} \mathbf{~ h r}$ & $\mathbf{4} \mathbf{~ h r}$ & $\mathbf{8} \mathbf{~ h r}$ \\
\hline Medium and large C\&I & & & & & \\
Cost per event & 6,558 & 9,217 & 12,487 & 42,506 & 69,284 \\
Cost per average kW & 8.0 & 11.3 & 15.3 & 52.1 & 85.0 \\
Cost per un-served kWh & 96.5 & 22.6 & 15.3 & 13.0 & 10.6 \\
& & & & & \\
Small C\&I & 293 & 435 & 619 & 2,623 & 5,195 \\
Cost per event & 133.7 & 198.1 & 282.0 & 1,195 & 2,368 \\
Cost per average kW & 1,604 & 396.3 & 282.0 & 298.9 & 296.1 \\
Cost per un-served kWh & & & & & \\
Residential & 2.1 & 2.7 & 3.3 & 7.4 & 10.6 \\
Cost per event & 1.4 & 1.8 & 2.2 & 4.9 & 6.9 \\
Cost per average $\mathrm{kW}$ & 16.8 & 3.5 & 2.2 & 1.2 & 0.9 \\
Cost per un-served $\mathrm{kWh}$ & & & & &
\end{tabular}


Table 5. The ten most severe blackouts.

\begin{tabular}{clccc}
\hline \multicolumn{1}{c}{ Country } & Year & Affected population & Duration \\
\hline 1 & New Zealand & 1998 & 70,000 & 4 weeks \\
2 & Brazil & 1999 & $97,000,000$ & 5 hours \\
& & & $(70 \%$ of the territory $)$ & \\
3 & India & 2001 & $226,000,000$ & 12 hours \\
4 & U.S.A. \& Canada & 2003 & $50,000,000$ & 4 days \\
5 & Italy & 2003 & $56,000,000$ & 18 hours \\
6 & Spain & 2004 & $2,000,000$ & 5 blackouts \\
& & 2005 & $100,000,000$ & 7 within 10 days \\
7 & Indonesia & 2006 & $15,000,000$ & 2 hours \\
8 & South West Europe & $87,000,000$ & 25 mins to 7 hours \\
9 & Brazil + Paraguay & 2009 & $53,000,000$ & 16 hours \\
\hline
\end{tabular}

quences of service disruption, Table 5 lists the ten most severe blackouts considering affected population and duration [16]. Cascading outages have been reported as the most important cause of recent major blackouts.

\subsection{Aging infrastructures}

A large number of components in the existing power systems have been designed and installed decades ago. As a matter of fact, by passing the time, failure rates of these components have increased significantly, which degrade ability of the grid to handle unexpected events. This is due to the fact that failure frequency of an old component is much more than that of a similar but new component. Aging power system components, in order to properly perform their functionality with reasonable failure rates, need regular costly maintenance and even replacement actions. These actions, however, seem very difficult considering number and geographical disparity of the components and also tightly limited budgets of the industry. Therefore, power industry is faced with the key challenging issue of aging infrastructures, which must be overwhelmed to achieve a resilient and sustainable power system.

\subsection{Cyber challenges}

While modern communication, control, and computing technologies offer tremendous opportunities to improve electric power system response and resilience to failure, they also render the grid vulnerable to intentional attacks from internal or external parties. This in fact increases the risk of compromising reliable and secure power system operation. In general, security attacks to the electricity infrastructure can be classified into physical and cyber threats. In case of physical threats, although the attacks may be troublesome and incur extra cost to the local grid owner, they are likely to affect only a small portion of the overall grid. On the other hand, the number of documented cyber-attacks and intrusions worldwide has been rising very rapidly in recent years. Due to the increasingly sophisticated nature and speed of malicious code, intrusions, and attacks, human responses may be inadequate. In addition, adversaries often have the potential to initiate attacks from nearly any location in the world. While the direct physical destruction may be the most obvious strategy for causing blackouts, cyber-attacks could also disrupt the system, cause blackouts, and in some cases, result in physical damage to key system components. As a result, cyber security is just as important as physical security and according to the abovementioned facts, special attention should be paid to this subject.

\section{Solutions}

The previous section provides a brief description of the most challenging issues which are faced by the electricity industry intending to achieve a resilient and sustainable system. This section gives the most effective solutions which have been proposed by power industry scientists and engineers. The solutions are asset management, renewable energy resources, demand response, controlled islanding and micro-grids, advanced automation systems, self-healing systems, and monitoring systems.

\subsection{Asset management}

Power systems are constituted by a large number of components which are subjected to different types of tensions ranging from corrosion, fatigue, and severe weather conditions to natural disasters and terrorist attacks. The resistance of the components against the tensions and their capacity to endure extreme conditions directly affect overall resiliency and sustainability of the power systems. Therefore, enhancing components ability to tolerate harsh conditions is a way to move toward a more resilient and sustainable power system. However, managing a large number of highly scattered components that have different types, 
ages, manufacturers, priorities, physical conditions, and required maintenance procedures is a challenging task. Asset management is the knowledge that strives to propel capabilities of the physical assets toward desired goals while observing technical and financial restrictions [17]. Recent practices of asset management in different industries and also in power systems have proved that asset management techniques are effective approaches that can greatly influence the system resiliency and sustainability while coping with limited budget and resources [18].

In asset management, service provider systematically looks to find the best strategies to acquire, upgrade, operate, maintain, and also dispose assets. It is worthwhile to mention that the best strategies have the ability to satisfy benchmarked resiliency and sustainability indices while meeting budget restrictions. The first step of asset management is to develop a few strategic plans for the service provider considering consumer needs, legislations, investors, and the business environment. Then, the risk associated with the developed strategic plans is assessed by taking available assets and scheduled asset-related procedures into account. Thereafter, final decision making is done based on the risks, organizational objectives, and available resources to determine physical asset-related strategies (i.e., acquisition, operation, maintenance, and disposal).

\subsection{Renewable energy resources}

As discussed earlier, energy crisis and environmental issues, nowadays, have been considered among the major concerns of humankind around the world. The first oil crisis in the early 70s was a wake-up call for human societies about the limited sources of fossil fuels and as a consequence, the need for sustainable sources of energy. To handle the issue, a few ideas have been proposed, among which were applying new technologies with higher efficiencies as well as moving toward the so-called 'clean energies' as promising alternatives for fossil fuels. Development and presence of renewable energies in energy markets can bring diversity to energy consumption and play a role in supplying energy services in a more sustainable manner. On the other hand, all the traditional energy sources pollute the environment while renewable energies are pollution-free and without negative effect.

The most popular and accepted technologies of renewable energies are wind energy, solar energy (direct, photovoltaic, and thermal), hydraulic (employing potential and kinetic energy of water), geothermal, bio-energy, etc. [19]. Based on the data published around the world, it is estimated that renewable energies supplied $12.9 \%$ of the total primary energy (492 EJ) in 2008 [11]. In addition, the contribution of renewable energies was almost $19 \%$ of global electricity supply in 2008. Although the share of the energies is still relatively small, their capacities are growing rapidly. In 2012, total installed renewable power capacity worldwide exceeded 1,470 GW. This means, in 2012, renewable energies comprised more than $26 \%$ of global generating capacity and supplied an estimated $21.7 \%$ of global electricity demand [20].

Renewable energy sources are usually available everywhere in the world. Furthermore, technologies which can harness these energies are also available and are improving rapidly. Therefore, they can play an important role in stepping toward a sustainable and resilient power system from the following aspects:

- Social and economic development: The economic development of a society is mainly correlated with per capita energy use. Therefore, one can come to this conclusion that electricity services with a higher quality are prerequisites of development. In this regard, renewable energies, taking their decentralized nature into account, can improve electricity service sustainability and resiliency in far and especially rural areas and as a consequence, play an important role in fostering rural developments;

- Energy access: In 2009, more than 1.4 billion people had no access to electricity. In addition, it has been forecasted that almost 1.2 billion people will request for electricity by 2015. As renewable energies are dispersed around the world, they can be a proper candidate for supplying the upcoming demand of energy. In particular, in rural regions, reliance on renewable energies will allow to attain universal access to modern energy services. The small size of renewable-based units such as photovoltaic, hydropower, and bio-energy can often meet the energy needs of rural regions more cheaply than conventional distributed generation technologies;

- Climate change mitigation and environmental concerns: As a key driving force, climate change mitigation can be achieved by growing the usage of renewable energies. In addition to decreasing greenhouse gas emissions, renewable energies also offer benefits with respect to air pollutions;

- Energy crisis concerns: Proliferation of renewable energy sources in power systems can alleviate dependence of the power industry on foreign fossil fuel markets, thereby mitigating energy crisis concerns.

\subsection{Demand response}

In the past, power system planners were responsible to predict future electricity consumption and make optimal reinforcement plans in order to serve the load. In such a way, the system was equipped with no driving force to motivate/force consumers to react in response to what was happening in the power industry. Having no active role in the power industry, consumers were 
passive players who plugged in their electric devices, consume electricity, and pay bills. However, in recent decades, power industry researchers have understood the value of demand response programs and the significant opportunity they offer to enhance sustainability and resiliency of the system while decreasing costs. They have found out that even a small portion of demand, which is flexible, can be an effective remedy to mitigate/alleviate the negative impact of several technical and financial issues. Demand response is referred to any voluntary effort to change normal consumption pattern with the objective of individual and/or social benefits. Demand response can be invoked when either power system resiliency and sustainability is jeopardized or electricity procurement cost is substantially raised. As found by engineers, a great portion of power industry issues can be mitigated by demand response potentials. For instance, a faint increment in electricity demand during peak periods might be translated into a significant increase in electricity procurement costs. Demand response can be used to decrease the peak load and thus, the procurement cost. Moreover, due to severe peak loads, a significant portion of power system facilities are installed to be utilized in a limited number of hours a year. This surely imposes significant monetary losses on the power industry. Demand response can be used to flatten the system load profile, therefore postponing a large number of power system reinforcements. Also, any unexpected outage in key generation or transmission system components during peak periods may impose significant risks on power system resiliency and sustainability. In such a situation, demand response, by reducing load, can increase safety margins of the system, thereby propelling it toward a more resilient and sustainable system.

In order to realize demand response potentials in a power system, there exist some approaches which can be grouped into two categories. These two categories are price based and incentive based programs. In a price based program, electricity service provider releases time-varying electricity prices, by which consumers are motivated to alter their normal consumption pattern such that some savings in electricity bills are obtained and power system sustainability is enhanced. In an incentive based program, however, a contract is signed between consumers and the service provider. The contract obliges the consumers to modify their consumption pattern upon receiving a signal from the service provider in exchange for some predefined monetary incentives.

\subsection{Controlled islanding and micro-grid}

As mentioned heretofore, power systems have been faced with catastrophic events such as the Aug. 14, 2003 blackout [21]. The power industry, in order to prevent such events, needs to develop new infrastructures

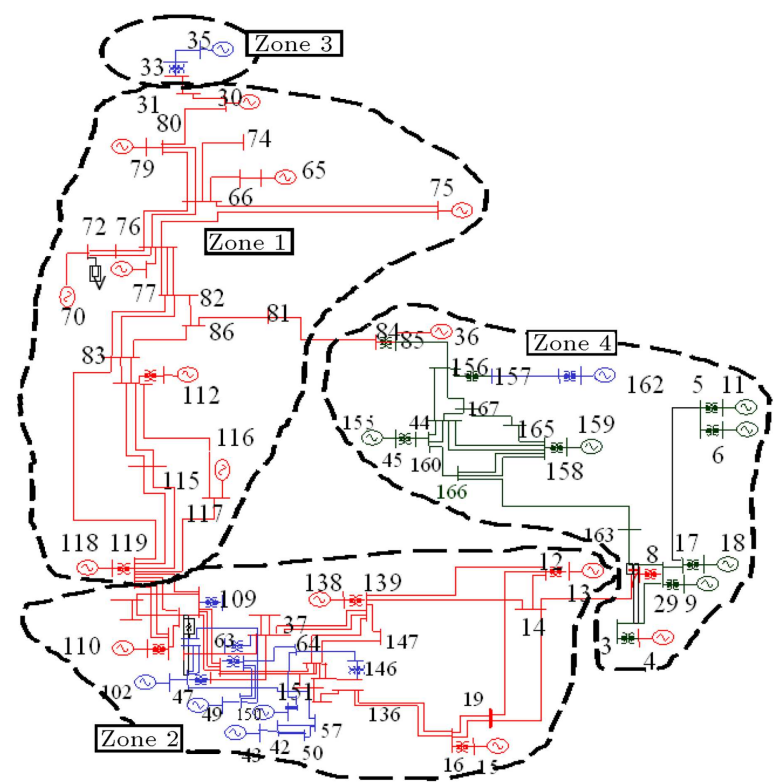

Figure 6. An extra-large power system constituting four sub-systems.

and operational concepts. A recently developed operational concept is controlled islanding. The main idea behind the concept of controlled islanding goes back to preventing propagation of faults through the whole system. In controlled islanding, the power system is divided into a few sub-systems which are able to be operated autonomously. The sub-systems are capable to be operated autonomously if they are connected to each other via weak boundary lines and active and reactive power balance conditions are met within each of the sub-systems. According to the concept, following a severe fault in a sub-system, boundary lines are mandatorily opened and healthy sub-systems will be operated autonomously. Figure 6 [22] shows an example of an extra-large power system which consists of four sub-systems. As can be seen, the sub-systems are connected to each other via three tie-lines.

Besides the concept of controlled islanding, which focuses on sub-systems in the transmission level, the concept of microgrid is another recently proposed idea, which focuses on sub-systems in the distribution level. Microgrid refers to a group of interconnected loads and generation units constituting a subsystem [23]. In fact, a microgrid can be considered as a very small vertically integrated electric utility in which there is no transmission component. In other words, generation and distribution components are the fundamental elements of a microgrid. A microgrid can operate in both grid-connected and islanding modes, since it has the ability to independently serve its loads with the power generated by its generation units. Thanks to this capability, following an event in the main grid, a microgrid can disconnect its loads and generation units from the grid and continue to serve its loads with the 
power generated by local generation. Consequently, microgrids, by serving loads even when the main grid is de-energized, have the potential to effectively improve resiliency and sustainability of power systems. Besides, they are equipped by additional control facilities which allow more distributed energy units to be connected to distribution networks, thereby alleviating environmental concerns and energy crisis issues.

\subsection{Advanced automation}

Power system automation is an effective tool by which system operators can promptly react in response to any unexpected event. In [24], advanced distribution automation is described as the "Heart of the Smart Power Delivery System". Automation will play a central role in providing enhanced levels of security, quality, reliability, and availability that are characteristics of a resilient and sustainable power system. Advanced automation systems are concerned with complete automation of all the controllable equipment and functions in the distribution level to improve distribution system strategic operation. The growing and changing role of electricity in our society, availability and need to use distributed generation resources, and the growing importance of service resiliency and sustainability are all drivers of advanced automation systems. The potential benefits of an advanced automation system include:

- Improved reliability and performance of distribution systems;

- Reduced operating costs;

- Enhanced contingency responses;

- Improved power quality;

- Increased customer service options;

- Prevention and mitigation of outages;

- Aid in outage recovery operations;

- Supporting integration of distributed energy resources into distribution operations;

- Making customer systems a part of the system performance equation.

\subsection{Advanced monitoring systems}

Monitoring systems provide power system control centers with an insight into current status of the system. Based on the system status, the online security analysis of power systems is performed in power system control centers to help system operators in operating power systems in a more resilient and sustainable manner. In recent decades, great efforts have been devoted to increasing accuracy of monitoring systems. Advanced monitoring systems are the result of the efforts. In the past, monitoring systems updated status of the system every 3-5 seconds while advanced monitoring systems update the system status several times a second. Measurements of conventional monitoring systems were asynchronous, which resulted in inaccuracies. However, measurements of advanced monitoring systems are equipped with an accurate time tagging system (which is based on the global positioning system) and as a result, their resulted system insight is much more accurate.

The more accurate the insight into the system status, which can be obtained using advanced monitoring systems, the more the benefits to resiliency and sustainability of power systems. Accurate system insight enables operators to more effectively take both preventive and corrective actions in the case of likely unexpected events. As noted earlier, efficient and secure communications are the prerequisites of an efficient monitoring infrastructure. Cyber-attacks may block or delay the delivery of the associated messages or even modify or falsify their contents. In this regard, strict authentication and authorization procedures should be implemented in the monitoring systems to ensure their security and dependability.

\subsection{Self-healing}

Traditionally, following an event, power system operators were informed about service interruptions by calls from affected consumers complaining about the curtailed supply. Upon receiving an interruption call, system operators by looking at the network topology and protection system settings approximately determined the interrupted area. Then, after the rough detection and localization of the interruption causes, a repair crew team was sent to patrol the area and manually fix the problem. However, this manual problem diagnosing and repairing process might take a long time, which could be translated into much more significant monetary losses and dissatisfaction of customers. In order to solve the issue, the idea of selfhealing systems was proposed by power industry researchers. A self-healing system is expected to respond to threats, material failures, and other destabilizing influences by preventing or containing the spread of disturbances [25]. In a self-healing system, thanks to monitoring and control technologies, system operators are informed about unexpected events by monitoring of network switches status. Any sudden change in status of network switches can be a signal of an event. Then, following the event detection, available remedial activities are utilized to restore electricity services to the interrupted customers. A self-healing system has to provide non-stop services in terms of:

- Providing situational awareness throughout the system;

- Predicting, preventing, and containing problems;

- Enforcing operational plans and required margins; 
- Supporting system restoration.

In order to realize a self-healing system, a highperformance IT infrastructure is needed to address gaps in the geographical and temporal coordination of power system monitoring and control. It is also essential to address a comprehensive set of operating concerns (in normal and abnormal conditions) that are associated with performance enhancement, adequacy of resources, and equipment and system operating limits, as well as primary and back-up protection of systems and components. In a self-healing system, not only the existing online analytical capabilities are envisioned to continue playing their role, but also the current offline capabilities must be integrated into the online environment. All these surely require the use of online decision support tools with intensive computational and communication requirements.

\section{Summary}

This paper focused on the topic of resiliency and sustainability in the electricity industry. In this regard, the most challenging issues encountered by the power industry as well as the most effective solutions proposed by the field researchers were thoroughly discussed. The challenges are load growth, energy crisis, emissions and climate changes, unexpected events, aging infrastructure, and cyber challenges. The set of solutions includes asset management, renewable energy resources, demand response, controlled islanding and micro-grids, advanced automation systems, self-healing systems, and monitoring systems. It is worthwhile to mention that the solutions are based on the degree of smartness in the system and can generally be categorized into two major groups. The first group contains those solutions which are on the basis of new advanced technologies such as monitoring and automation systems. On the other hand, the second group is devoted to solutions which are based on the existing procedures but with more systematic routines and in a more effective manner. Asset management is an example for the second group of solutions.

According to the existing literature, an electricity system in which the pointed solutions are realized is referred to a smart grid or grid of the future. This coincidence goes back to the fact that resiliency and sustainability of electricity services were constituted as the main criteria in developing a roadmap for electricity systems in the future. A typical smart grid is shown in Figure 7 [26]. In the following, effectiveness of the solutions in the electricity system is briefly described:

- Asset management: The system has a large number of elements including wind turbines, photovoltaic panels, circuit elements, and switches, each of which has a failure rate. As mentioned earlier in this paper, failure rate of a typical component usually increases substantially through the time. In the considered system, the operator addresses the issue using effective asset management strategies, by which optimal candidate elements for maintenance or replacement actions are identified. This is a positive step toward achieving a sustainable and resilient system in a cost-effective manner;

- Renewable energy resources: As can be observed in Figure 7, the system contains a large number of renewable-based generating units (wind turbines and photovoltaic panels). The green power produced by the units not only alleviates environ-

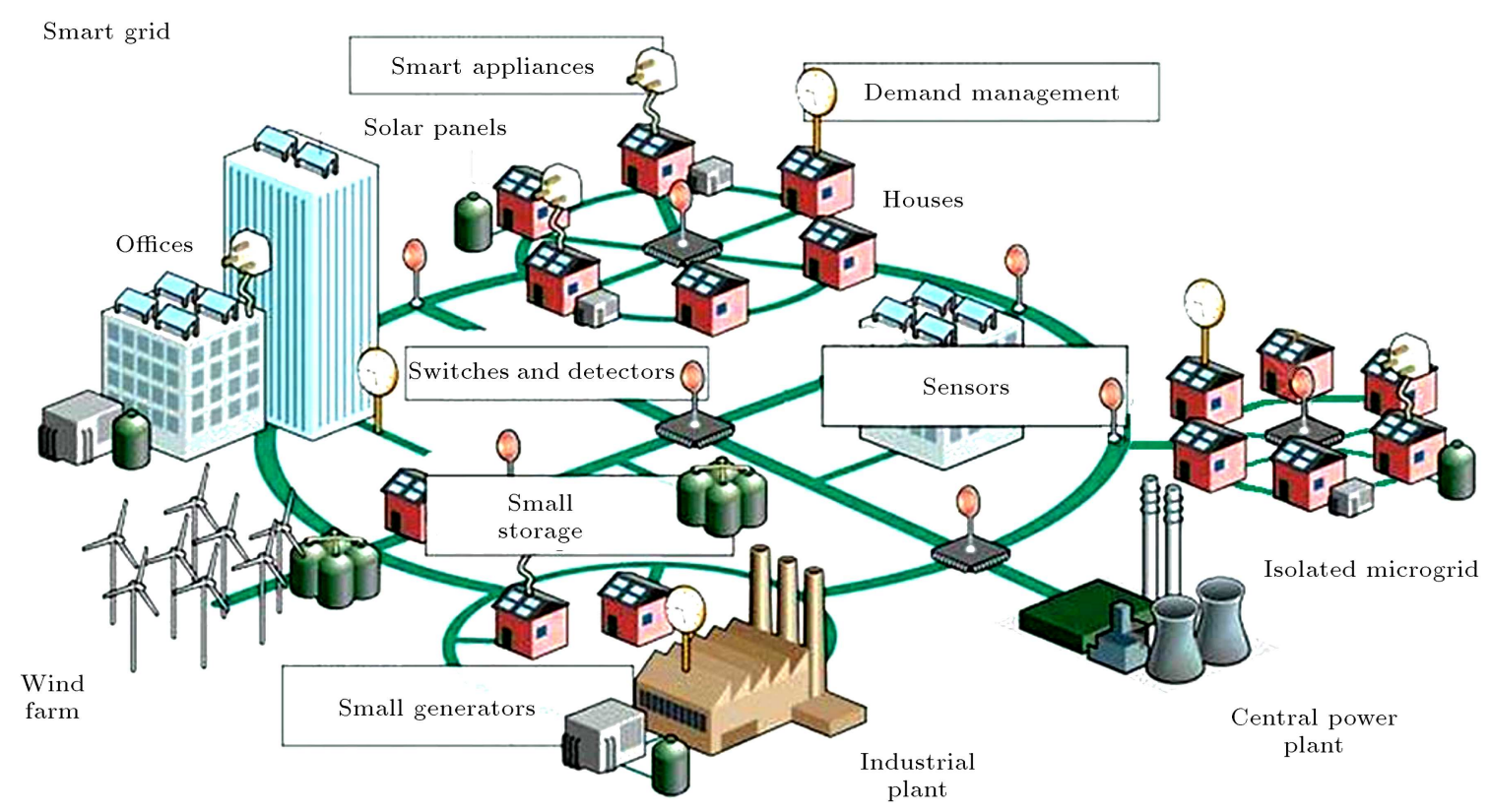

Figure 7. A typical resilient and sustainable electric power system. 
mental concerns, but also reduces dependency of the system on diminishing sources of fossil fuels. These sustainable energy resources can propel the system toward more resiliency and sustainability as well;

- Demand response: As can be observed in Figure 7 , demand response potential of some flexible loads is activated in the system. Operation of the flexible loads can be postponed to a later time, whenever any violation in operating conditions is experienced. Doing so, service interruptions, which were conventionally invoked to alleviate the violations, are avoided and thus, resiliency and sustainability of the system are enhanced;

- Controlled islanding and micro-grids: The system contains central power plants as the conventional way of energy procurement as well as some smaller generating units dispersed almost all over the territory. In three cases (pointed by smaller network loops), a group of loads and generating units have established micro-grids. The micro-grids, although connected to the main grid during the normal condition, can serve their loads autonomously in an isolated manner. This can be counted as a step toward a more sustainable and resilient system since the loads connected to the micro-grids can be supplied even when the main grid experiences supply interruptions;

- Advanced automation: As can be seen in Figure 7 , the system is equipped with a few remote controlled switches embedded in the shown detectors. These switches, following an unexpected event, can be used to isolate the faulted area and restore energy supply to likely interrupted loads. Owing to the fast switching actions, which are possible thanks to the automatic remote switches, load restoration can be done promptly, thereby improving the system resiliency and sustainability and thus, convenience of customers;

- Advanced monitoring system: The at-hand smart system is equipped with an advanced monitoring system, by which the operators sitting in the control center can trace the current state of the system and predict occurrence probability of any likely event. Therefore, the operators can decide about the most appropriate remedial actions, which should be invoked to minimize possible unpleasant effects of the events. Besides, the system can be operated under lower security margins, which in turn can be translated into a more resilient and sustainable situation even with lower operating costs;

- Self-healing: As can be seen in Figure 7, a few detectors and switches are embedded in the system. Moreover, the system is designed such that loads can be supplied by at least two independent parallel routes.

Accordingly, once an unexpected event occurs, the faulted area can be detected based on the status of the detectors. Then, appropriate switching actions can be performed to isolate the detected area and serve loads from an alternative route. In this system, fault detection and isolation as well as service restoration to affected loads can be done automatically in a very short time. Self-healing systems with automatic and prompt responses to events can result in a more resilient and sustainable electricity system.

\section{References}

1. Coaffee, J. "Risk, resilience, and environmentally sustainable cities", Energy Policy, 36(12), pp. 4633-4638 (2008).

2. Available from: https://www.iea.org/publications/freepublications/publicatio n/KeyWorld2013.pdf.

3. Gopalakrishnan, K. and Peeta, S., Sustainable and Resilient Critical Infrastructure Systems, Verlag Berlin Heidelberg, Springer (2010).

4. Holling, C.S. "Resilience and stability of ecological systems", Annu. Rev. Ecol. Syst., 4, pp. 1-23 (1973).

5. Wildavsky, A., Searching For Safety, Transaction Publishers, New Jersey (1991).

6. Comfort, L.K., Shared Risk: Complex Systems in Seismic Response, Pergamon, New York (1999).

7. Analysis Center (NISAC) report to the U.S. Department of Homeland Security (September 11, 2008).

8. Billinton, R. and Fotuhi-Firuzabad, M. "A basic framework for generating system operating health analysis", IEEE T Power Syst., 9(3), pp. 1610-1617 (1994).

9. Energy Information Administration "Annual Energy Outlook 2007 with Projections to 2030", U.S. Department of Energy, Feb. 2007 [Online]. Available: ftp://tonto.eia.doe.gov/forecasting/0383(2007).pdf.

10. Available from: http://www.tavanir.org.ir.

11. Available from: https://www.iea.org/publications /freepublications/publication/KeyWorld2013.pdf.

12. Available from: https://www.bp.com/statisticalreview.

13. Kothari, D.P. and Nagrath, I.J., Modern Power System Analysis, Tata McGraw-Hill Education (2003).

14. Kirschen, D. and Strbac, G., Fundamentals of Power System Economics, Wiley, New York (2004).

15. Contolella, P., Farber-DeAnda, M., Greening, L.A. and Kim, T., Estimates of The Value of Uninterrupted Service For The Mid-West Independent System Operator Paul Centolella SAIC, Midwest Independent Transmission System Operator (2006). 
16. Bruch, M. Münch, V. Alchinger, M. Kuhn, M. Weymann, M. and Schmid G. Power Blackout Risks: Risk Management Options Emerging Risk Initiative Position Paper, CRO Forum (Nov. 2011).

17. Waeyenbergh, G. and Pintelon, L. "Maintenance concept development: A case study", Int. Jour. Product. Economics, 89, pp. 395-405 (2002).

18. Setr'eus, J., Identifying Critical Components For System Reliability in Power Transmission Systems, Doctoral dissertation, Sch. Elect. Eng., KTH, Stockholm, Sweden (2011).

19. Bostan, V., Sobor, I., Bostan, I., Dulgheru, V., Sochirean, A. and Gheorghe, A.V., Resilient Energy Systems - Renewables: Wind, Solar, Hydro, 1st., Ed., Springer (2013).

20. Available from: https://www.ren21.net/.

21. Ye, Z., Walling, R., Miller, N., Du, P. and Nelson, K., Facility Microgrids, National Renewable Energy Laboratory, New York (2005).

22. Vittal V. and Heydt, G.T. "The problem of initiating controlled islanding of a large interconnected power system solved as a Pareto optimization", IEEE PES Power System Conference and Exposition, Seatlle WA (2009).

23. Mader, E.D. and King, J. "Microgrids in New England technical challenges \& opportunities", Connecticut Light \& Power (2012).

24. "Investigation of the technical and economic feasibility of micro-grid based power systems", EPRI Technical Report 1003973, Interim Report (2001).

25. Amin, M.S. and Wollenberg, B. "Toward a smart grid", IEEE Power Energy M, 3(5), pp. 34-41 (2005).

26. Amin, M.S. and Wollenberg, B. "Toward a smart grid", IEEE Power Energy M, 3(5), pp. 34-41 (2005).

\section{Biographies}

Mahmud Fotuhi-Firuzabad (F'14) received the BS degree from Sharif University of Technology, Tehran, Iran, in 1986, the MS degree from Tehran University, Tehran, in 1989, and the MS and PhD degrees from the University of Saskatchewan, Saskatoon, SK, Canada, in 1993 and 1997, respectively, all in Electrical Engineering. Currently, he is a professor in the Department of Electrical Engineering, and president of Sharif University of Technology. He is a member of the Center of Excellence in Power System Management and Control. Dr. Fotuhi-Firuzabad serves as an Editor of the IEEE TRANSACTIONS ON SMART GRID.

Amir Safdarian (S'11-M'15) received the BSc degree from Tehran University, Tehran, Iran, in 2008, and the MSc and $\mathrm{PhD}$ degrees from Sharif University of Technology, Tehran, in 2010 and 2014, respectively, where he is currently an Assistant Professor. He is also collaborating with the Power Systems and High Voltage Engineering Research Group, Department of Electrical Engineering and Automation, Aalto University, Espoo, Finland. He was a recipient of the 2013 IEEE Power System Operation Transactions Prize Paper Award. His research interests include power system reliability and resilience, distribution network operation and planning, and smart grid issues.

Moein Moeini-Aghtaie received the MSc and $\mathrm{PhD}$ degrees from Sharif University of Technology, Tehran, Iran, in 2010 and 2014, respectively, in Electrical Engineering. He is currently an Assistant Professor in Sharif Energy Research Institute, Department of Energy, Sharif University of Technology, Tehran, Iran. His current research interests include reliability and resilience studies of modern distribution systems, especially in the multi-carrier energy environment, and charging management of plug-in hybrid electricvehicles (PHEVs).

Rahim Ghorani received the BSc degree from Isfahan University of Technology, Isfahan, Iran, and the MSc degree from Sharif University of Technology in 2013 all in Electrical Engineering. He is currently pursuing the $\mathrm{PhD}$ degree and is a member of Power System Reliability Laboratory, Sharif University of Technology. His research interests include power system resiliency and reliability, asset management, and maintenance scheduling.

Mohammad Rastegar received the BSc, MSc, and $\mathrm{PhD}$ degrees from the Sharif University of Technology, Tehran, Iran, in 2009, 2011, and 2015, respectively, all in Electrical Engineering. He joined the School of Electrical and Computer Engineering, Shiraz University, Shiraz, Iran, in 2016. His current research interests include modeling home energy management systems, plug-in hybrid electric vehicle operation, and power system reliability and resiliency studies.

Hossein Farzin received the BSc degree (with distinction) in Electrical Engineering from Sharif University of Technology, Tehran, Iran, in 2011, where he is currently pursuing his $\mathrm{PhD}$ studies. His research interests include smart grid, integration of electric vehicles and renewable energy in distribution systems, microgrids analysis and optimization, cyber security, and power system reliability and resilience. 